\title{
ANALISIS KARYA POSTER BERDASARKAN UNITY, LAYOUT, TIPOGRAFI, DAN WARNA
}

\author{
Yohana Agatha Kembaren ${ }^{*}$, Gamal Kartono ${ }^{2 *}$, Mesra $^{3 *}$ \\ Program Studi Pendidikan Seni Rupa Jurusan Seni Rupa Fakultas Bahasa dan Seni \\ Universitas Negeri Medan \\ Jl. Willem Iskandar Pasar V Medan Estate, Kec, Percut Sei Tuan, Kab. Deli Serdang, Kode Pos 20371 \\ Sumatera Utara. Indonesia \\ Email:kimagyoagyo@gmail.com
}

\begin{abstract}
Abstrak
Penelitian inibertujuan untuk, mendeskripsikan dan menginterpretasikan hasil karya poster peserta didik kelas XII IPS SMA Negeri 1 Kabanjahe, yang ditinjau berdasarkan unity (kes atuan), layout (tata letak), tipografi, dan warna. Populasi dalam penelitian ini berjumlah 24 karya poster peserta didik dengan sampel berjumlah 3 karya (12,5\% dari total populasi) dan teknik yang digunakan adalah purposive sample. Data dianalisis menggunakan metode deskriptif kualitatif dengan cara mengetahui hasil validasi yang dilakukan validator, kemudian hasil validasi dianalisis berdas arkan kategoris asi yang berkaitan dengan objek yang diteliti yang meliputi kesatuan (unity), tataletak(layout), tipografi, dan warna. Dari total 24 karya peserta didik, kary a no 5 memperoleh nilai terting gi (94) ,nilai sedang dengan kategori baik karya no 17 (89) dan no 22 kategori baik dengan nilai terendah (86,5). Sebanyak 11 karya (46\%) memperoleh predikat sangat baik (A) dan sebanyak 13 karya (54\%) memperoleh predikat baik (B). Berdasarkan analis is diperoleh kesimpulan hasil bahwa nilai pada aspek unity (kesatuan), didapat rerata berjumlah 89, 25, untuk layout (tata letak), dengan nilai rerata 89,41, tipografi dengan nilai rerata 88,29, dan warna dengan nilai rerata 88,95 . Secara umum rerata untuk empat kategori dapat dinterpretasikan berkualitas baik.
\end{abstract}

Kata Kunci: poster, kesatuan, tata letak, tipograi.

\begin{abstract}
The research aims is to describe and interpret the posters work of the $12^{\text {th }}$ social grade students (XII SOS 1) Public Senior High School 1 Kabanjahe (SMA Negeri 1 Kabanjahe), which are reviewed based on unity, layout, typography, and color. The population in this study amounted to 24 poster works by students with 3 sample works (12.5\% of the total population) The technique used in this research is purposive sample. Data were analyzed using qualitative descriptive methods by knowing the results of the validation conducted by the validator, then analyzing the results of the validation based on the categorization relating to the object under study which includes unity, layout, typography, and color, then the results of the validation were analyzed based on the categorization relating to the object under study which included unity, layout, typography, and color. From a total of 24 works of students, work No. 5 received the highest score (94), intermediate value which in the good category work No.17(89) and number 22 which good category with the lowest score (86.5). The Total of 11 works (46\%) received an excellent rating $(A)$ and 13 works (54\%) received a good rating $(B)$.Based on the analysis, the conclusion of the research results shows that the value of the aspect of unity obtained an average of 89, 25, for the layout with an average value of 89.41, typography with a mean value of 88.29 , and color with a mean value 88.95. In general, the results of the mean scores for the four categories can be interpreted as good quality.
\end{abstract}

Keywords: poster, unity, layout, typography.

\section{PENDAHULUAN}

Mata pelajaran Seni Rupa memiliki peran potensial yang dapat mendukung dan mewujudkan kepribadian manusia Indonesia seutuhnya melalui karya Seni Rupa, diantaranya adalah poster. Pendidikan Seni Rupa dapat membantu menumbuhkan karakter pada setiap pribadi yang mempelajarinya melalui kegiatan apresiasi dan kreasi.

Berdas arkan observasi y ang dilakukan di SMA Negeri 1 Kabanjahe, Kecamatan Kabanjahe, Kabupaten Karo, peserta didik diketahui kurang memahami cara dan langkah-langkah membuat karya poster yang baik 
banyak ditemukan dari karya peserta didik tersebut tidak menerapkan azas-azas atau prinsip-prinsip poster sepertipenerapan azas unity (kesatuan), penerapan layout (tata letak), penerapan tipografi, dan penerapan warna. Umumnya prinsip-prinsip tersebut sering terabaikan sehingga tidak menimbulkan interaksi yang harmonis yang mengakibatkan pesan yang terkandung dalam poster tidak tersampaikan sebagaimana mestinya kepada pembaca.

Berdas arkan hasil observasi dan wawancara dengan guru, peneliti tertarik untuk mengetahui serta memahami karateris tik gambar peserta didik dengan menganalis isnya berdas arkan unsur maupun prinsip visual seni rupa dalam poster, yang bertujuan untuk lebih mengenal karya seni poster peserta didik.

\section{KAJIAN TEORI}

\section{Pengertian Analisis}

"Analisis adalah suatu analisa yang dilakukan berdas arkan jumlah data yang diperoleh, selanjutnya dikembangkan pola hubungan tertentu menjadi hipotesis" (Sugiyono, 2011 : 335) sedangkan menurut Daldiyono (2009 : 110) "Analisis adalah sikap atau perhatian terhadap sesuatu (benda , fakta , fenomena) sampai mampu menguraikannya menjadi bagianbagian , serta mengenal kaitan antarbagian tersebut dalam keseluruhan". Maka yang dianalis is dan yang akan diuraikan dalam penelitian ini adalah poster karya peserta didik kelas XII IPS SMA Negeri 1 Kabanjahe T.A 2018/2019 berdas arkan unity, layout, tipografi, dan warna.

\section{Pengertian Menggambar}

Menurut Gumelar (2015 : 8) "Menggambar adalah suatu kegiatan untuk menghasilkan gambar". Menggambar cenderung membuat goresan (stroke) dan membuat coretan (outline). Menggambar berasal dari kata "Gambar" yang artinya membuat atau menciptakan gambar. Gambar (drawing) beras al dari kata draw yang berarti menggambar. Gambar berfung si sebagai fakta yang memperlihatkan pikiran dan rencana dalam kreativitasnya (Susanto, 2011 : 145). Gambar eks presi dapat diartikan sebagai hasil coret-mencoret pada bidang dua dimensi dengan maksud menampilkan suatau wujud tertentu yang awalnya sudah dirasakan terlebih dahulu oleh manusia atau siseniman (Sitepu, 2020: 34). Maka dapat disimpulkan meng gambar adalah hasil gores an dalam sebuah bentuk yang tercipta pada bidang dua dimensional. Penciptaan gambar tersebut di atas merupakan hasildari belajar sepanjang masa, dimana belajar merupakan "kemampuan yang dimiliki oleh
Gorga : Jurnal Seni Rupa

Volume 09 Nomor 01 Januari-Juni 2020

p-ISSN: 2301-5942 | e-ISSN: 2580-2380

seseorang s etelah menerima pengalaman belajar yang meliputi seluruh mental" (Mesra, 2016: 308).

\section{Pengertian Poster}

Susilana dan Riyana (2009: 14), mengatkan bahwa "Poster yaitu sajian kombinasi visual yang jelas, menyolok, dan menarik dengan maksud untuk menarik perhatian orang yang lewat". Pada karya yang telah terkumpul mas ih banyak ditemukan penerapanpenerapan prinsip, unsur, dan elemen-elemen antar desain yang masih kurang memuaskan untuk dapat disebut sebagai karya poster yang sempurna dan menarik.

Isanto (dalam Limah, dkk, 2018 : 37) mengatakan bahwa "Poster adalah gambar pada selembar kertas sebagai salah satu alat untuk menyampaikan sebuah pesan yang ditempel atau digantung pada tembok. Poster terdiri dari kes atuan gambar (tanda visual) dan tulisan (tanda verbal) yang mengahasilkan efek sederhana, komunikatif, dan estetik". Poster merupakan karya seni rupa terapan dua dimensional yang berfungsi sebagai sarana promosi aneka jenis produk maupun jasa dan juga termasuk untuk propaganda aneka gagasan (Kartono 2014 : 131 ).

Susilana dan Riyana (2009: 14), menjelaskan bahwa "Poster yaitu sajian kombinasi visual yang jelas, menyolok, dan menarik dengan maksud untuk menarik perhatian orang yang lewat". Pada karya yang telah terkumpul masih banyak ditemukan penerapanpenerapan prinsip, unsur, dan elemen-elemen antar desain yang masih kurang memuaskan untuk dapat disebut sebagai karya poster yang sempurna dan menarik.

\section{Jenis-Jenis Poster}

Kusrianto (2007 : 338) berpendapat bahwa poster dapat dibedakan menurut fungsinya, yaitu "Poster propaganda, poster kampanye, poster wanted, poster cheesecake, poster film, poster buku komik, poster affirmation, poster di dalam kelas , poster karya seni, dan poster komersial". Dalam penelitian ini hanya akan dibatasi dan dibahas pada jenis poster buku komik karya peserta didik kelas XII IPS SMA Negeri 1 Kabanjahe.

\section{1). Poster Buku Komik}

Popularitas komik dunia mencapai puncaknya pada tahun 60-an. Hal ini memicu produksi massal posterposterkomik pada tahun 70-an ke atas. Di Indonesia sendiri booming poster komik kurang begitu dirasakan, karena saat itu justru komik Indonesia sedang jaya-jayanya. Di tahun 90-an bermunculan 


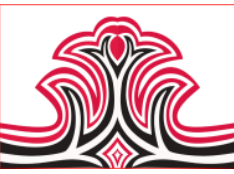

poster tokoh-tokoh manga, seperti Dragon Ball, Sailor Moon, Hing ga Harry Potter.

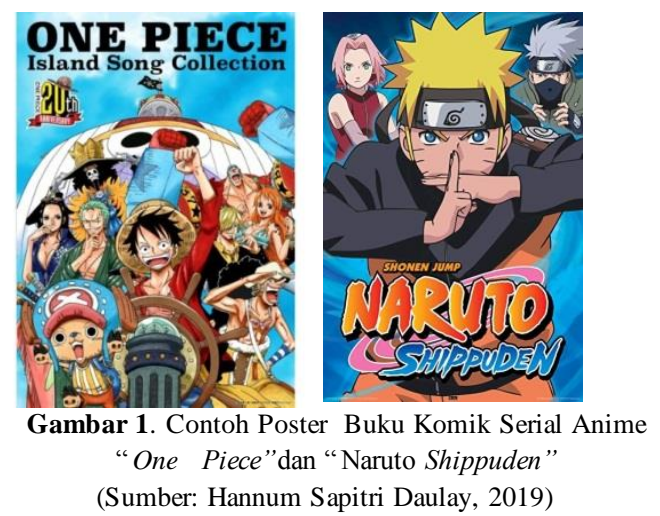

\section{Unsur-Unsur Rupa dalam Desain Poster}

Anggraini ( 2014 : 32) mengatakan "Unsur-unsur desain terdiri dari garis, bentuk, tekstur, gelap terang/kontras, ukuran, warna"Unsur- unsur ini wajib dikenali oleh perupa atau pendesain agar mampu mengangkat nilai-nilai yang terkandung di dalamnya , serta mentransformasikan gagas an ke dalambidang dua dimensi.

\section{Pengertian Unity (Kesatuan)}

Zulkfli (dalam Saragih dan Zulkifli, 2019 : 274), berpendapatbahwa "Kesatuan (unity) adalah bagian dari prinsip komposisi tata rupa, yang harus diperhatikan dalamberkarya seni rupa. Kesatuan atau disebutjuga keutuhan adalah kualitas hubungan antara bagian-bagian dari elemen komposisi yang menyatu, baik dalam bentuk visual ataupun tema (content). Kesatuan atau kepadu an munculdidalamketung galan. Bagian yang satu deng an yang lainnya saling terkait, saling menentukan, saling mendukung dan sistemik mewujudkan keutuhan visualisasi karya. Tanpa adanya kesatuan karya seni maupun desain akan terlihat cerai berai".

\section{Tata Letak (Layout)}

Menurut Rustan (2017 : 1) “Layout dapat dijabarkan sebagai tata letak elemen-elemen desain terhadap suatu bidang dalammedia tertentu untuk mendukung konsep/ pesan yang dibawanya". Selanjutnya (Poulin, 2018 :58) mengatakan bahwa "A harmonious and dynamic compositional layout is composed of a combination of continuous text-filled and image activated fields (or modules)", yang bila diartikan kedalam bahasa Indoneia yaitu tata letak komposisi yang harmonis dan dinamis tersusun dari sebuah kombinasi kolom yang diisi teks dan bidang (ruang) gambar yang aktif. Menurut Rustan (2017 :74) "Prinsip dasar layout adalah juga prinsip das ar desain
Gorga : Jurnal Seni Rupa

Volume 09 Nomor 01 Januari-Juni 2020

p-ISSN: 2301-5942 | e-ISSN: 2580-2380

grafis, diantaranya adalah : a) Urutan (Sequence) , b) Penekanan (Emphasis), c) Keseimbangan (Balance), d) Kesatuan (Proximity)".Rustan (2017 : 28) mengatkan "Layout memiliki banyak sekali elemen yang mempunyai peran yang berbeda-beda dalam memebangun keseluruhan layout". Elemen layout dibagi menjadi elemen teks dan elemen visual.

\section{Tipografi}

Kartono dan Sembiring (2017 : xvi) mengatakan “ Tipografi adalah suatu sarana komunikasi visual yang sangat berarti oleh manusia, dan huruf merupakan saksi yang menuliskan dan menceritakan peradaban manusia selama berabad-abad lamanya".Selanjutnya Ariani dan Banjarnahor (2018:1041) berpendapat bahwa "Tipografi adalah seni huruf meliputi pemilihan huruf, penentuan ukuran huruf, penentuan ukuran yang tepat dimana teks dapat diputus, seperti jarak dan bagaimana teks dengan mudah dibaca". Tipografi sebagai salah satu elemen desain yang mempengaruhi dan dipengaruhi oleh elemen desain yang lain, serta dapat mempengaruhi keberhasilan suatu karya desain secara keseluruhan. Elemenelemen tipografi yang dimaksud adalah Legibility dan Readability (Anggraini, 2014 : 64).

\section{Warna}

Bentuk atau benda apapun di alam ini pasti mempunyai warna bila terdapat cahaya. Warna juga merupakan unsur rupa yang paling mudah ditangkap mata manusia. Hal ini sesuai dengan pendapat Nugroho (2015 : 22), yang berisi “ Warna merupakan fenomena getaran/gelombang yang diterima indera penglihatan". Warna merupakan usnsur yang paling mudah menimbulkan kesan pada perasaan, sehingga merupakan yang paling akrab dikenal manusia. Swasty $(2010: 10)$ mengatakan teori Brewster yakni "Teori ini menyederhanakan warna-warnayang ada di alam menjadi empat klasifikasi warna yaitu warna primer, sekunder, tersier, dan netral". Sedangkan menurut Swasty (2010 : 11) bila dilihat dari hubungannya warna dapat dibagi atas " warna komplementer, warna split komplementer, warna triad komplementer, warna tetrad komplementer, warna monokromatik dan polikromatik, warna analogus".

\section{METODE PENELITIAN}

Metode penelitian yang digunakan yaitu metode peneltian kualitatif. Teknik pengumpulan data yang digunakan observasi dan dokumentasi. Alat dan bahan peneltian yang digunkan yaitu kamera dan lembar penilian. Teknik analisis data yang digunakan yaitu deskriptif kualitatif. 


\section{HASIL DAN PEMBAHASAN \\ 1.Hasil}

Berdasarkan data yang telah diambil dari table penilaian, maka hail penilaian secara kes eluruhan dari indikator-indikator yang diteliti pada karya poster peserta didik kelas XII IPS SMA Negeri 1 Kabanjahe dapat dikategorikan baik denganjumlah rata-rata $=89$, dengan penjabaran seperti berikut :

-Aspek penilaian (Unity / Kesatuan) memperoleh jumlah nilai $=2142$ dengan rata-rata $(r)=88,25$ (Baik).

-Aspek penilaian (Layout / Tata letak) memperoleh jumlah nilai $=2146$ dengan rata-rata $(r)=89,41$ (Baik).

-Aspek penilaian Tipografi memperoleh jumlah nilai $=$ 2119 dengan rata-rata (r) = 88,29 (Baik).

-Aspek penilaian warna memperoleh jumlah nilai $=$ 2135 dengan rata-rata $(r)=88,95$ (Baik).

Berikut ini adalah sampel sebanyak 3 karya $(12,5 \%)$ karya dari populasi 24 karya peserta didik yang diurutkan berdasarkan perolehan nilai tertinggi, yaitu karya Dea Mira Chris tin Haloho, karya Kezia Perbina Ginting, dan Karya Erik Imanuel .P.

\section{Pembahasan}

\section{1). Karya 1}

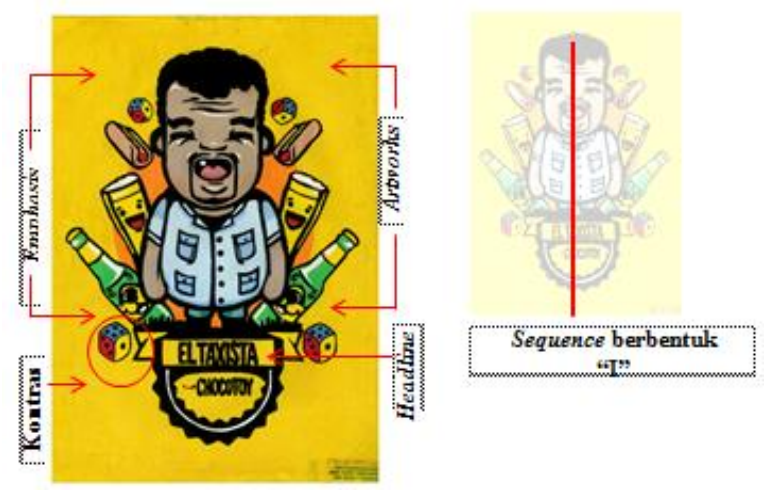

Gambar 2. Karya Dea Mira Christin Haloho (Sumber: Yohana Agatha Kembaren, 2019)

Berdasarkan analisis dan penilaian yang telah dilakukan oleh apresiator, dapat ditarik kesimpulan dapat diinterpretasikan data yang diperoleh dari 3 orang apresiator pada poster buku komik karya Dea dalam kategori kesatuan (unity), tata letak (layout), tipografi, dan warna. Analis is data secara keseluruhan dari 3 orang apresiator memperoleh nilai 93. Menurut peneliti karya ini layak mendapat nilai 95 karena gambar pada poster sudah mengkomunikasikan isi dari pesan yang akan disampaikan, dimana warnawarna yang diterapkan sudah mencerminkan keceriaan. Dapat disimpulkan karya ini memperoleh nilai dari ahli dan peneliti $(93+95) / 2=94$ kategori Sangat Baik (A).

Aspek Kesatuan (unity) pada poster karya Dea mendapat perolehan nilai sebanyak 281 dengan ratarata 94, masuk kedalam kategori sangat baik (A). Kesatuan antar objek bentuk manusia, bentuk geometris, sepertidadu, botol, setengah lingkaran, dan persegi panjang yang dibuat bervariasi, berdekatan sesuai dengan kemiripan-kemiripan objeknya.

Aspek Tata letak (layout) pada poster karya Dea mendapat perolehan nilai sebanyak 281 dengan ratarata 94, masuk kedalam kategori sangat baik (A). Penempatan gambar tepat di tengah kertas, dan membentuk sequence "T". Jarak antar gambar dan tulisan juga sudah baik, space diatur dengan baik. Kes eimbangan poster ini adalah jenis keseimbangan formal atau simetris. Gambar (artworks) yang dibuat variasi besar kecil merupakan unsur yang menjadi penekanan emphasis) disini.

Aspek Tipografi merupakan salah satu unsur terpenting dalamdesain sebuah poster.Perolehan nilai untuk tipografi padaposter ini adalah 276 dengan nilai rata-rata 92, termasuk kedalam kategori sangat baik (A). Pada karya ini hanya ada satu jenis huruf yang digunakan, yaitu roman (huruf tegak), yang diterapkan pada judul. Tipografi merupakan salah satu unsur terpenting dalamdesain sebuah poster.Perolehan nilai untuk tipografi pada poster ini adalah 276 dengan nilai rata-rata 92, termasuk kedalam kategori sangat baik (A). Pada karya ini hanya ada satu jenis huruf yang digunakan, yaitu roman (huruf tegak), yang diterapkan pada judul.

As pek Warnapada karya ini kaya akan variasi warna dan berhasil menampillkan kesan ceria. Perolehan nilai untuk warna ini adalah 281 dengan nilai rata-rata 94, termasuk kedalamkategori s an gat baik (A). W ama kuning digunakan sebagai background karya ini. Warna background yang cerah sangat tepat penerapannya dan menonjolkan warna-warna cerah yang terdapat pada gambar dan tulisan. Kontur gelap/hitam yang terdapat pada gambar juga sangat menunjang kontras antar background dan gambar. 


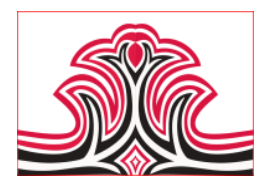

2). Karya 2

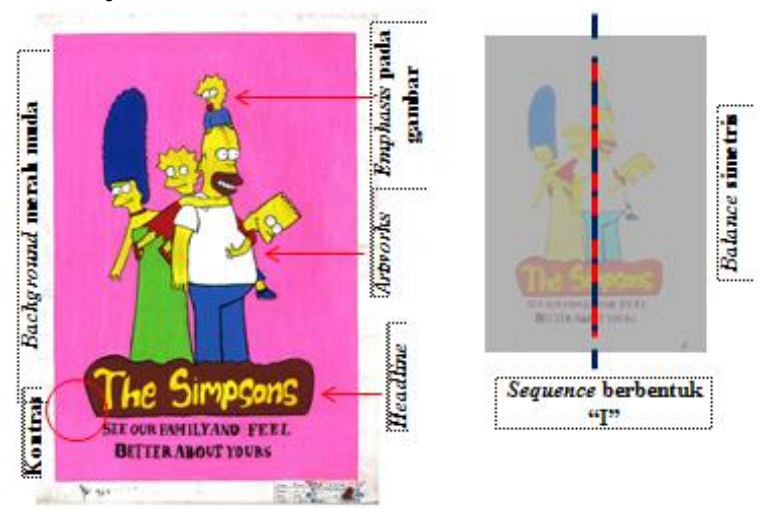

Gambar 3. Karya Kezia Perbina Ginting (Sumber: Yohana Agatha Kembaren, 2019)

Berdasarkan analisis dan penilaian yang telah dilakukan oleh apresiator, dapat ditarik kesimpulan dapat diinterpretasikan data yang diperoleh dari 3 orang apresiator pada poster buku komik karya Kezia dalam kategori kesatuan (unity), tata letak (layout), tipografi, dan warna. Analis is data secara keseluruhan dari 3 orang apresiator yaitu memperoleh nilai 89. Menurut peneliti karya Kezia mendapat nilai 90, karena sudah membuat poster yang hampir sesuai dengan dasar-dasar penyusunan poster, dan menurut para apresiator karya poster ini mendapat nilai 89 , oleh karena itu dapat disimpulkan bahwa karya ini mendapat nilai $(89+90) / 2=89,5$, dengan kategori Baik (B).

Aspek kesatuan (unity) pada poster karya Kezia mendapat perolehan nilai sebanyak 270 dengan ratarata 90, masuk kedalam kategori sangat baik (A). Keterpaduan antar unsur-unsur tipografi dan gambar dalam karya sudah baik dan saling mendukung.

Nilai pada aspek layout (tata letak) pada poster ini baik (B) berjumlah 263 dan rata-rata 88. Pada karya ini urutan baca berbentuk pola "I".

Keseimbangan pada poster ini adalah jenis keseimbangan simetris, dimana sisi kanan dan kiri bobotnya sama dan saling menyesuaikan walaupun bentuknyadan penempatannya berbeda. Penekanan pada karya ini terdapat pada pada gambar utama.

Perolehan nilai pada aspek tipografi pada karya ini adalah 268 dengan rata-rata 89, kategori baik (B). Huruf yang digunakan pada karya inibergay a roman yang beberapa hurufnya diberi penggayaan. Keterbacaan teks pada karya ini sudah baik, karena huruf-hurufnya sudah legible dan mudah dikenali. Variasi huruf antara judul dengan teks pendukung juga sudah baik.
Gorga : Jurnal Seni Rupa

Volume 09 Nomor 01 Januari-Juni 2020

p-ISSN: 2301-5942 | e-ISSN: 2580-2380

Aspek warna pada karya ini memperoleh nilai sebanyak 70 , dengan rata-rata 90 , termasuk dalam kategori sangat baik (A). Pada background warna yang diterapkan adalah merah muda dngan value (nilai) yang lebih gelap. Variasi warnya yang terdapat pada gambardan teks yang cenderung warna-warna kuat dan cerah, menghasilkan kontras yang tajam dengan background.

\section{3).Karya 3}
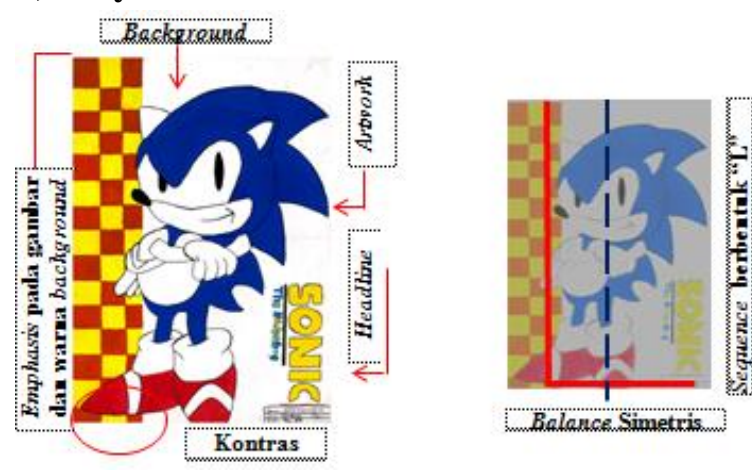

Gambar 4. Karya Erik Imanuel $P$

(Sumber: Yohana Agatha Kembaren, 2019)

Berdasarkan analisis dan penilaian yang telah dilakukan oleh apresiator, dapat ditarik kesimpulan dapat diinterpretasikan data yang diperoleh dari 3 orang apresiator pada poster buku komik karya Erik dalam kategori kesatuan (unity), tata letak (layout), tipografi, dan warna. Analis is data secara keseluruhan dari 3 orang apresiator yaitu memperoleh nilai 82,75. Menurut peneliti karya Erik layak mendapat nilai 88. Maka dari itu dapat disimpulkan karya ini memperoleh nilai dari ahli dan peneliti $(82,75+88) / 2$ $=85,37$ kategori Baik $(\mathbf{B})$.

Aspek esatuan (unity) pada poster karya Erik mendapat perolehan nilai sebanyak 254 dengan ratarata 84, masuk kedalam kategori baik (B). . Keterpaduan antar unsur-unsur dalam gambar sudah baik dan saling mendukung. .Keterpaduan antara background, teks, dan gambar sudah baik. Keutuhan atau kesatuan merupakan tujuan akhir yang harus dicapai dalam penyusuann komposisi desain , agar hasil dari suatu karya dapat dikatakan menarik dan baik.

Aspek layout (tata letak) pada poster ini baik (B) berjumlah 246 dan rata-rata 82. Pada karya ini urutan baca berbentuk pola "L". Mata akan pertama kali melihat background yang terlihat kontras dan gambar utama, kemudian akan dituntun untuk melihat judul yang terdapat pada bagian kanan bawah 1 . Pemanfaatan space (ruang) sudah termasuk baik. Pada 
sisi kiri latar belakang dibuat dan diatur bentuk pola background yang berbeda dengan sisi kanan yang berwarna polos/putih. Dengan begitu sisi background putih merupakan tempat yang tepat untuk menempatkan judul, agar komposisi tidak terkesan terdapat pada satu sisi saja.. Jarak antar teks dang mbar juga sudah bagus tidak ada yang saling berhimpit. Keseimbangan pada poster ini adlah jenis keseimbangan simetris, dimana sisi kanan dan kiri bobotnya sama dan saling menyesuaikan walaupun bentuknyadan penempatannya berbeda. Penekanan pada kary a ini terdapat pada paduan background dan objek gambar yang terlihat sangat menonjol daripada judul.

Nilai Aspek tipografi pada karya ini adalah 246 dengan rata-rata 82 , kategori baik (B). Huruf yang digunakan pada karya ini bergaya roman. Keterbacaan teks pada karya ini sudah baik, karena huruf-hurufnya sudah legible dan mudah dikenali. Variasi huruf antara judul dengan teks penjelas juga sudah baik.

Aspek Warna pada karya ini memperoleh nilai sebanyak 246 , dengan rata-rata 82 , termasuk dalam kategori baik (B). Pada background warna yang diterapkan duahbaik yatitu perpaduan warna kuning, merah, dan putih. Disisi kiri space, background dipenuhi warna merah dan kuning yang sudah terpola, di sisi kanan putih polos. Warna ini kemudian menjadikan kontras dengan objek gambar dan juga kepada teks yang terdapat pada sisi yang berwarna putih.

\section{KESIMPULAN DAN SARAN \\ 1.Kesimpulan}

Berdasarkan hasil analisis pada karya diatas, dapat disimpulkan aspek unity (kesatuan) memperoleh kategoribaik, layout (tata letak) memperoleh kategori baik, tipografi memperoleh kategori baik, dan warna memperoleh kategori baik.

\section{Saran}

Bagi Kepala Sekolah, perhatian dan dukungan dari kepala sekolah terhadap pembelajaran seni budaya (rupa) diharapkan dapat menunjang keberhasilan proses belajar mengajar seni budayadi SMA Negeri 1 Kabanjahe. Bagi Guru, sebagai acuan untuk peningkatan kualitas pembelajaran seni rupa pada bahasan poster. Agar pengajar dibidang kesenirupaan lebih memperdalam pengetahuan dan wawasan mengenai teori -teori poster. Bagi Penggiat Seni/ Komunitas Seni, sebagai bahan rujukan dan pertimbangan untuk berkarya seni poster. Bagi
Gorga : Jurnal Seni Rupa

Volume 09 Nomor 01 Januari-Juni 2020

p-ISSN: 2301-5942 | e-ISSN: 2580-2380

Peneliti, bagi peneliti, untuk menambah wawasan dan pengetahuan dan bagi peneliti selanjutnya yang ingin melakukan penelitian dapat menjadi kajian dasar.

\section{DAFTAR RUJUKAN}

Anggraini S, Lia., Natalia, K. (2014). .Desain Komunikasi Visual : Dasar-Dasar Panduan Untuk Pemula.Bandung : Nuansa Cendekia.

Daldiyono. (2009). How to Be a Real and Successful Student. Jakarta : PT Gramedia Pus taka Utama.

Gumelar, M.S. 2015. Elemen \& Prinsip Menggambar . E-book : An 1mage Studio.

Kartono, Gamal . (2014). Poster . Medan : Unimed Press.

Kartono, Gamal dan Sembiring Dermawan. Tipografi Dalam Desain Komunikasi V Medan : Al-Hayat.

Kusrianto, Adi. (2007). Pengantar Desain Komunikasi Visual . Jakarta : Andi

Limah, Hutri. dkk. (2018). Poster Upaya Mempertahankan Kemerdekaan Indonesia di Yogyakarta Tahun 1945-1949 . Journal Of Indonesia History, 7 (1), 35-44.

Mesra, M., Azis, A. C. K., \& Astuti, W. W. (2016). Kontribusi Motivasi Belajar Dan Lingkungan Tempat Tinggal Terhadap Hasil Belajar Mahasiswa Jurusan Seni Rupa Universitas Negeri Medan. Jurnal Bahas Unimed, 27(3), 302-319.

Nugroho, Sarwo. (2015) . Manajemen Warna dan Desain. Yogyakarta : Andi.

Poulin, Richard. (2018). Design School Layout. USA: Quarto Publishing Group.

Rustan, Surianto .2017a . HurufFont Tipografi Edisi 2017. Jakarta : PT . Gramedia Pustaka Utama.

Saragih, L. A., \& Zulkifli, Z. (2018). Analis is Kerajinan Souvenir Diorama Berbahan Limbah pada Pengrajin Dikraf Berdasarkan PrinsipPrinsip Desain. Gorga: Jurnal Seni Rupa, 8(1), 272-278.

Sitepu, C., Azmi, A., Ibrahim, A., \& Azis, A. C. K. (2020). Tinjauan Gambar Ekspresi Objek Manusia Berdasarkan Teori Lowenfeld Menggunakan Krayon oleh Anak TK B Methodist Berastagi. Gorga: Jurnal Seni Rupa, 9(1), 32-38.

Sugiyono. (2011) . Metode Penelitian Kualitatif, Kuantitatif, dan $R \& D$. Bandung: Alfabeta.

Susilana , Rudi dan Riyana. (2009). .Media Pembelajaran Hakikat Pengembangan Pemanfaatan dan Penilaian. Bandung : CV. Wacana Prima

Swasty, Wirania . (2010). A-Z Warna Interior : Rumah Tinggal . Jakarta : Griya Kreasi. 